\title{
An Exploration of College English Teaching Mode from the Perspective of Intercultural Communication
}

\author{
Ma Rongqin \\ Humanity \& International Education College, Xi’an Peihua University, Xi’an, China \\ 511914519@qq.com
}

Keywords: intercultural communication, college English teaching, college English teaching mode

\begin{abstract}
: with the continuous enhancement of globalization, people from different cultural backgrounds need not only language communication, but also the practice of intercultural communication ability based on understanding each other' $\mathrm{s}$ culture to achieve effective communication. College students, as the mainstream group in this era, not only want to know about each other's national culture through language communication, but more importantly, cultivate each other' s intercultural communication ability in the process of English learning. Colleges and universities, as the main position of cultivating college students, should construct a scientific college English teaching model from the perspective of intercultural communication in order to carry out international cultural communication more effectively.

In China, intercultural communication is the product of the reform and opening-up policy. After the reform and opening up in 1978, China opened its door to the world with the emergence of intercultural communication in China. In recent decades, as a new interdisciplinary subject, intercultural communication has been developing rapidly in the context of globalization. If we want to be in an advantageous position in the globe communication, we should learn to understand the culture of other countries, reduce the resistance in communication and avoid misunderstandings caused by cultural differences when interacting with others. In the meantime, we will cultivate high-quality, highly specialized type of person to engage in exchange, so that foreign friends can understand the Chinese culture and development. With the exchange of talents, China has already joined in the new field of intercultural communication. Therefore, we have to reflect on college English teaching mode in China and how to innovate it, in order to make talents become more outstanding in the field of intercultural communication, which have become the key issue concerned by people from all walks of life. Based on these points, this paper will explore them and put forward some personal opinion.
\end{abstract}

\section{Intercultural communication profile}

\subsection{The meaning and importance of intercultural communication}

People from different languages or countries interact with each other in languages, which we call it intercultural communication. In these different backgrounds, people talk through language, and language is the bond of connection. It can be said that the language used by each country has its original characteristics and national nature. Only by understanding the culture of a country and integrating the cultural background into the language can it really play the role of communication. Therefore, the cultivation and application of intercultural communication in college English teaching become crucial.

The purpose of college English teaching is to cultivate high quality English professionals, so as to achieve cultural and economic exchanges between countries. Therefore, in addition to having good listening, speaking, reading and writing skills, English talents need to understand the culture of relevant countries, so as to integrate into the language communication. In the process of cross-cultural communication training, it's not just about the input of the traditional culture of the students, but it's also about teaching students to understand the language used by native speakers, 
the method of thinking, the way of life, and the manner that they can interact and learn in the way that they want to be, which is an effective way for cross-cultural interaction. College English curriculum consists mainly of the understanding and extension of traditional culture, in which the university English teachers should be able to consult and collect data on the national characteristics of the relevant countries, and make the lectures, so that they can be added to the course, which can connect the content to the practice. It allows students experience the atmosphere of different cultural backgrounds in the classroom, so as to constantly improve their English practice and application ability.

Theoretically, the culture in the cross-culture also contains language, the combination of language and its culture as well, but they have differences in nature. The most important thing to learn a language is to learn the culture of the country so as to improve learners' oral English. The cultivation of college students' English intercultural communication ability is beneficial to promote the development and innovation of education in China and to lash Chinese examination-oriented education system; to cultivate students' English learning ability and interest, and enhance their social skills; to cultivate students' ability of intercultural communication, and be able to understand foreign culture more comprehensively.

\subsection{Intercultural communication mainly posses the following characteristics of:}

\subsubsection{Different cultures}

The formation of cross-cultural communication is caused by the exchange of cultures among different countries, which belong to different countries' backgrounds.

\subsubsection{Common language characteristic}

People in different languages need to use the same language when conducting an exchange to achieve interactions and applications. Therefore, we call this feature as common language characteristic.

\subsubsection{Directness of oral expression}

Cross-cultural communication between two people is usually conducted through oral expression and face-to-face communication.

\section{Advantages and disadvantages of college English teaching from the perspective of intercultural communication}

\subsection{Main advantages of college English teaching in the field of intercultural communication}

Once the reform of college English teaching in the field of intercultural communication is realized, students will be successful in learning English from the perspective of connotation and essence. There is no fixed pattern in English teaching, but the existing rules are easy to grasp. From the perspective of intercultural communication, teachers can easily help students find the methods and essence of English learning through cultural infiltration, which is often more effective than the theoretical explanation. On the other hand, the realization of cross-cultural communication is conducive to strengthening the communication and understanding between students and teachers, enhancing the effective interaction in the classroom and making the teaching mode more novel.

\subsection{Deficiencies in college English teaching from the perspective of intercultural communication}

Everything has two sides. The advantages of intercultural communication are obviously greater than the disadvantages. However, it is undeniable that intercultural communication still has disadvantages in China. 


\subsubsection{Learning English from the perspective of foreign countries and cultural concepts will inevitably weaken Chinese culture}

In the case of infiltration of foreign ideas, whether students can reasonably publicize foreign ideas will determine their understanding of local culture. Based on the analysis of the status quo of Chinese English teachers, it is found that foreign teachers barely know about Chinese culture and relevant characteristics, and even have prejudice and misunderstanding on some etiquette. Once college students have prejudice on the understanding of local culture, it will seriously affect college students' outlook on life, world view and values, and more seriously, it will lead to college students being unable to serve as the main force of China's future development. It can be said that if this problem occurs, it will deviate from the original intention of the development of intercultural communication.

\subsubsection{The progress and difficulty of the course are unable to master}

The traditional education system is so ingrained that students have been forced to accept learning since childhood. However, the idea of intercultural communication advocates students' active exploration of knowledge and realizes the benign interaction between teachers and students. The teacher has to focus on the key points of the course in the context of cross-cultural interaction, which brings out the key points to the other, to improve student's ability to learn and to speak English. Once the open and advanced teaching concept is fully applied in Chinese education courses, it is difficult to grasp the course process and the time of lectures, and teachers' own level and English ability may not be able to effectively control the classroom. Another problem is that students themselves will relax in this teaching mode, which cannot guarantee classroom discipline. In this way, cross-cultural communication need to truly be popularized, and it is necessary for Chinese educational organization to make a vigorous exploration.

\section{Construction of college English teaching mode from the perspective of intercultural communication}

Faced with the deficiency of college English teaching in the context of intercultural communication and the increasing demand of society for intercultural communication talents, the construction of a scientific college English teaching model has become an inevitable trend of the development of college English education. In this paper, based on the analysis of intercultural communication and the opportunities and challenges posed by college English teaching under the background of cross cultural communication, and also with reference to the computer technology application and the multimedia teaching mode in the college English curriculum teaching, a basic model college English teaching is tried to constructed, which aims at developing students' intercultural communication ability .In the following article, we have a detailed analysis and discussion about this teaching model based on teaching objectives, teaching content, teaching principles, teaching methods, teaching methods and evaluation.

\subsection{Teaching objectives}

According to the theoretical research achievements of the international intercultural research circle and the actual teaching situation of college English in China, the overall teaching goal of college English can be set as: to improve the basic language ability and communicative ability of English learners at most, and to cultivate the intercultural communication ability of English learners, in which language proficiency specifically refers to mastering basic language knowledge such as pronunciation, grammar and vocabulary, as well as language skills such as listening, speaking, reading, writing and translation; communicative competence refers to the ability to conduct relevant communication activities correctly and appropriately, including corresponding language and pragmatic competence; intercultural communication ability refers to the social communication ability that has gone beyond the specific language scope and corresponding cultural groups, and can 
flexibly use one's own language knowledge and skills according to different language-used conditions.

\subsection{Teaching contents}

Since the teaching objectives of college English from the perspective of intercultural communication mainly include three aspects: language competence, communication competence and intercultural communication competence, the teaching contents should be unified with the teaching objectives, starting from the three aspects of language teaching, cultural cognition teaching and the cultivation of students' intercultural communication competence. Through the teaching of the target English language and culture, learners can gradually master the target language and cultural knowledge, and be able to use this language to communicate with the corresponding language groups normally and effectively in the intercultural English teaching practice. At the same time, the learners are also cultivated to consciously reflect on their own native language in the learning activities, and to know the general law of development between the two languages and the basic cultural constitute, and to clarify the inner link between language development and its social and cultural background and experience purpose language culture in the process of actual communication, reflect their national culture. In the comparison between the target language culture and national culture, the students' sensitivity to the differences between cultures should be enhanced, so as to achieve the emotional transfer of the target language culture. With the proper guidance and help of teachers, the students should truly grasp and effectively solve the possible cultural conflicts and cultural misunderstandings in cross-cultural communication. The three important areas are closely linked by teaching contents, specifically the language and cultural knowledge is the basis of English learning; the specific use of language and the perception of cultural differences provide practical learning opportunities for the internalization of knowledge, in which intercultural awareness is cultivated in the basic knowledge learning of English teaching. At the same time, cultural learning provides learners with corresponding preparation for practical exchange of ideas, which is ultimately able to cultivate learners' intercultural communication ability in the teaching practice of intercultural communication.

\subsubsection{Teaching principles}

The analysis of teaching objectives and contents mentioned above has embodied two important principles that intercultural communication English teaching must follow, namely, the integrated development principle of the balance of cultural teaching and the organic combination of language and culture teaching. In addition, teachers should adhere to the following two principles in intercultural communication English teaching, so as to cultivate students' intercultural communication ability. One is the principle of student-centered teaching activities, in which students are the main body of the teaching activities and the teaching activities must revolve students and satisfy their actual study demand. In the practice of intercultural English teaching, the cultivation of students' intercultural communication ability should be based on students, and the students' language learning needs, attitudes and different abilities should be included in the teaching design. Teaching students according to their aptitude will promote their all-round development. Another is the principle of interaction. There is a co-existing relationship between equal dialogues and communication in Chinese and western cultures, especially in the context of globalization, where interaction among cultures is more pronounced. English teaching in the context of intercultural communication should also follow this law of social development and give full play to the mutual promotion of Chinese and western language learning. In the process of teaching practice, the traditional single-way information transmission teaching concept should be changed appropriately according to the new teaching mode, meanwhile, the two-way cultural transmission and interaction in the teaching process should be emphasized. In addition, the interaction between teachers and students is also an important part of the principle of teaching interaction. Teachers can influence students' learning life through teaching activities, while students can influence teachers' teaching behavior by the way of the doubts and innovation consciousness generated in the learning process. Intercultural communication itself is a two-way interactive communication form, in which 
language teaching is gradually developing. Therefore, intercultural English teaching must attach importance to the interactivity in the teaching process, give full play to students' awareness of teaching participation, and improve the actual teaching effect.

\subsubsection{Teaching methods}

English teaching in China has introduced a series of teaching methods, such as translation method, direct method, audio-lingual method, cognitive method and communicative method, according to the teaching needs. In modern society, task-driven method, a new type of teaching method, has been explored, which has an important impact on the improvement of teaching effect. The following is a detailed discussion on the traditional communicative approach and the new task-based approach. Communicative approach, originated in the 1970s, was first established by the English-speaking countries. It is believed that the main purpose of language teaching is to cultivate students' ability to communicate with target language. The content of language teaching practice should include not only the basic language teaching structure, but also various related ideas of language itself and main functions that students need to master. Communicative method focuses on the cultivation of students' language ability, and advocates that students' communicative ability should be exercised in designed communicative situations in class, which is conducive to the cultivation of students' intercultural communicative ability. However, the communicative approach has some defects. It is easy to indulge students' mistakes in language learning, which is not conducive to students' long-term development. Task-based teaching method means that teachers carry out teaching activities by setting teaching tasks and guiding students to complete tasks in teaching practice. Task-based teaching method emphasizes that "learning by doing" in teaching practice. Teachers should design a series of operational teaching tasks, while students can gradually complete the teaching tasks through such language activities as independent inquiry or group communication, so as to achieve the purpose of strengthening the learning effect, which is conducive to the construction of students' knowledge system and the formation of comprehensive language application ability

\subsubsection{Teaching evaluation}

Culture teaching is one of the important contents in intercultural English teaching, and the subjectivity of culture itself promotes the generation of teaching evaluation. As the traditional quantitative evaluation testing method cannot meet the practical needs of intercultural English teaching, the qualitative evaluation testing method taking the real evaluation and performance evaluation as the main content emerges. Teachers can make a comprehensive evaluation of students' learning activities through students' learning process, the degree of effort, learning attitude, progress and ultimate learning effect, while students can also reflect on their own learning performance according to teachers' evaluation and improve their learning effect. Compared with the traditional evaluation method, this method is conducive to stimulating students' learning enthusiasm, helping students to timely find problems in their study and life and make timely adjustments, which is scientific and advanced to a certain extent.

All in all, in the context of intercultural communication, the mode of college English teaching takes the cultivation of students' intercultural communication ability as the ultimate teaching goal, the cultivation of students' language ability and communicative ability as base, the cultivation of language and culture teaching and students' intercultural communication ability as the main content, which can integrate language teaching, communicative ability teaching and culture teaching into a comprehensive and three-dimensional teaching mode, so as to meet China's intercultural communication needs in international cultural communication.

\section{Acknowledgement}

This paper is the periodical achievement of Shaanxi Province Education Science "The Thirtenn Five-year" Planning Project: An Exploration of the Optimization of the Teaching Programs for English Majors in Local Applied Universities from the Perspective of Needs Analysis-Based on the 
Survey of Graduates with the Project number of SGH17H460.

\section{References}

[1] "College English Teaching Guide" (Ministry of Education the latest version) 2017

[2] Yongjun Cheng. Discussion on the adaptability of intercultural communication context in college English teaching [J]. English square, 2013 (9): 100.

[3] Jinhua Fan. College English teaching from the perspective of intercultural communication [J]. School, 2014 (18): 81-81.

[4] Xiaoli Qu. College English teaching from the perspective of intercultural communication [J]. Journal of capital normal university (social science edition), 2012 (3): 102-105.

[5] Huoyan Wang. Research on college English teaching model based on cross-cultural communication [D], Wuhan: Huazhong University of Science and Technology, 2012.

[6] Wei Zhao. Case teaching research based on the cultivation of intercultural communication ability. [J]. Journal of Henan Institute of Science and Technology, 2012, (6) 